\title{
Cultural Differences between Asians and Non-Asians affect Buying Attitudes and Purchasing Behaviours towards Green Tourism Products
}

\author{
Suk Ha Grace Chan'1, Ka Yin Chau² ${ }^{2 *}$ \\ ${ }^{1}$ Faculty of International Tourism and Management, City University of Macau, Macau, China \\ ${ }^{2}$ Faculty of Business, City University of Macau, Macau, China \\ Email: gracechan@cityu.mo, ${ }^{\star}$ gavinchau@cityu.mo
}

How to cite this paper: Chan, S. H. G., \& Chau, K. Y. (2021). Cultural Differences between Asians and Non-Asians affect Buying Attitudes and Purchasing Behaviours towards Green Tourism Products. Journal of Service Science and Management, 14, 241-261.

https://doi.org/10.4236/jssm.2021.143015

Received: February 23, 2021

Accepted: May 8, 2021

Published: May 11, 2021

Copyright $\odot 2021$ by author(s) and Scientific Research Publishing Inc. This work is licensed under the Creative Commons Attribution International License (CC BY 4.0).

http://creativecommons.org/licenses/by/4.0/

\begin{abstract}
Green tourism products include environment-friendly hotels adopted in recyclable goods and facilities; airlines decided to reduce carbon emissions to tackle climate change; such examples have been widely promoted over the past decade. This study explores the cultural differences between Asians and non-Asians in the context of buying attitudes and behaviour related to green tourism products. A qualitative exploratory approach was used to examine the attitudes of Asian and non-Asian tourists when selecting green tourism products and to investigate how cultural differences affect buying behaviour to provide recommendations to tourism marketers developing strategies to promote tourism products. Thirty destination visitors from 11 countries took part in in-depth interviews. The Asian visitors' attitudes towards green tourism products were influenced by their cultural norms and their governments' implemented policies. Non-Asian attitudes were affected by individual norms and beliefs. The findings highlight an Asians focus on pricing, whereas non-Asians consider quality and style more than pricing when buying green tourism products. Marketing messages that target Asian visitors should use emotional appeals and link to their historical background. Those that target non-Asians should emphasise individual responsibility. The paper provides practical guidelines for international tourism marketers who plan to target various markets.
\end{abstract}

\section{Keywords}

Asian, Attitude, Cultural Differences, Green Tourism Product,

Purchase Intention, Non-Asian 


\section{Introduction}

In today's highly competitive environment, the hospitality sector has adopted "green" branding to promote tourism products and compete with "non-green" businesses. Early cultural research critics have noted that there is evidence that cultural background may affect tourist behaviour (Pizam \& Jeong, 1996). Hotel business going for green such practice includes saving water, energy and reducing the waste. Airlines decide to reduce the carbon emissions in the air which can reduce the global warm climates. Many hospitality sectors their behaviour tend to be green and environmental friendly cause to marketing promotion. One empirical study found that visitors from developed countries differed in their environmental awareness, beliefs and buying behaviour compared to those from developing countries (Singh \& Gupta, 2013). According to Yen et al. (2017), this raises the question of whether the decision to purchase green products is led by cultural differences between Asian and non-Asian customers.

Soderbert and Holden (2002) highlighted that failure to handle cultural differences properly will lead to misunderstanding and service failure. Reisinger and Turner (2002) noted that cultural differences between Asian and Non-Asian tourists are reflected in differences in the time spent on various activities and in patterns of recreation, leisure and travel behaviour. Early Pizam and Sussmann (1995) noted that behavioural differences between visitors from Asian and non-Asian countries were attributable to cultural influences. Current green tourism research focuses on willingness to pay an additional amount, positive attitudes and buying behaviour (Pereira, Mykletun, \& Hippolyte, 2012). Other research has highlighted that in Western cultures, gender differences influence environmental perceptions, values and actions (Agarwal, 2000). However, scholars have paid little attention to whether cultural differences between Asians and non-Asians affect buying attitudes and purchasing behaviour in relation to green products. Many travellers' selections of tourism products are determined by price and facilities (Mey et al., 2006). Based on Hofstede (1991)'s cultural dimensions theory, researchers have concluded that Asians and non-Asians differ in their values and norms (Crotts \& Erdmann, 2000), and that these factors explain and affect their buying decisions and behavioural intention (Liu, Liu, \& Mo, 2019). Under the culture differences in values, beliefs and attitudes may influence non-Asians' and Asians' interest in buying green tourism products. It is worthwhile to further examine both groups. This paper therefore attempts to answer the following questions:

1) Does cultural background affect tourists' choice of green tourism products?

2) Does environmental consciousness affect attitudes towards buying green tourism products?

3) Do Asian and non-Asian cultures have similar attitudes when engaging in green purchasing behaviour?

The aim of this study was to investigate whether cultural differences affect values, attitudes and behaviour from Asian and non-Asian perspectives to en- 
hance tourism industry practitioners' understanding of visitors' needs and wants and provide recommendations to tourism marketers about how to market green products. A further aim was to add to the literature on how cultural values may influence the performance of environmentally friendly acts. The study contributes to understanding of Asian and non-Asian tourists' attitudes and behaviour in the context of green tourism products, and it provides a road map for tourism marketers by outlining the cultural gaps between Asian and non-Asian visitors buying green tourism products.

\section{Literature Review}

\subsection{Corporate Environmental Commitment to Green Tourism Products}

Considerable research and practice has been devoted to environmental policymaking in many countries over the past 30 years. Government and non-private sectors play a decisive role in the development and implementation of environmental policy. However, governments and regulatory bodies alone have not been able to implement sustainable environmental development management instruments over the past decade; therefore, the tourism industry has made efforts to adopt green policies and practices. Manaktola and Jauhari (2007) argued that marketers appeared to have assumed that a green product was a guarantee of success. However, when designing tourism products, it is necessary to handle cultural differences properly. Judicious handling of cultural differences may lead to competitive advantage. Scholars highlighted culture perceived as a communication or resources for organisation learning (Soderbert \& Holden, 2002). For marketers if they can understand the culture differences from their customers, they might make use of right communication strategies to target their potential customers for the future.

Many hospitality organisations have focused on eco-labelling practices and benchmarking (Pereira, Mykletun, \& Hippolyte, 2012). Airlines attempt to obtain recognition, particularly the recognition of ISO 14000 or Green Globe 21, for their environmental efforts. Awarding bodies provide guidelines for airports and airlines and apply accreditation systems in the commercial aviation sector. The high number of green awards that airlines gain results in a substantial amount of positive word-of-mouth from their customers.

Hotels are frequently associated with issues related to the deterioration of the environment. They cause considerable harm to the environment due to the excessive consumption of non-recyclable goods, water and energy for heating and air conditioning. The Hilton Group and Hyatt Regency Hotels have implemented reduced-power programmes and energy-saving devices. Green hotels major concerns protect nature in green under the three major areas such as energy conservation programs, waste reduction programs and water conservation programs (Yi, Li, \& Jai, 2018). Many customers prefer to stay in eco-rooms, which provide business opportunities for hotel groups (Han et al., 2019). 
Others initiatives, such as the Tour Operator Initiative for Sustainable Tourism Development and the Cruise Industry Waste Management Practices and Procedures Program (Weaver, 2008), indicate that the industry is trying to promote green tourism products. Corporate organisations have adopted green labels to improve their brand image, which enhances competitiveness. Many people perceive that green tourism products fulfil customers' environmental consciousness needs and add value to the organisation, saving costs (Pereira, Mykletun, \& Hippolyte, 2012). Five factors drive environmental responsibility among tour operators and create special effects (Miller, 2001): industry structure and the level of competition; legal requirements from the government; public relations and marketing benefits for going green; long-term cost-savings balanced against the short-term nature of tourism business operations; and moral obligations. These practices are indicated by green tourism product labels, so tourists can make their own decisions. Green management can enhance customer satisfaction, market demand (Manaktola \& Jauhari, 2007) and corporate image (Penny, 2007).

Green tourism products fulfil a customer need. However, tourists from different countries and regions may make different buying decisions about green products, which is worthy of examination.

\subsection{Environmental Attitudes and Behaviour in Relation to Green Products}

Kotchen and Reiling (2000) found a positive relationship between environmental attitude and environmental behaviour. According to Homer and Kahle (1998), values influence attitudes and attitudes influence behaviour. An individual who exhibits a positive attitude towards the environment has concern for environmental issues and a focus on social benefits. This attitude may drive him or her to purchase green products (Cheung \& To, 2019). Previous studies have identified environmental behaviour and behavioural intention and reported that consumers' positive attitude towards the environment relates to green purchase intentions. If consumers know that a product is beneficial for society, then they will be willing to pay an additional amount (Kumar et al., 2017; Lin \& Huang 2012). Ricky, Chan, \& Lau (2000) claimed that attitudes towards green purchases could affect green purchase behaviour via the mediator of green purchase intention. Environmental consciousness affects consumers' attitudes towards buying green goods, which influences their intention to buy products (Kim \& Chung, 2011).

Several studies have found that knowledge of ecological issues is a key determinant of environmentally friendly behaviours, including green product purchases. All of the components of consumer purchasing attitudes towards green products are encompassed by theory regarding values, attitudes and behaviour, whereas cultural differences may affect attitudes and behaviour (Liu et al., 2019). Mayo and Jarvis (1981) highlighted that cultural differences may cause different nationalities to perceive things differently. Manaktola and Jauhari (2007) argued customers are not willing to support green practice because most green projects 
are governmental in India. Cultural differences can shape the buying attitudes of hosts and the tourists they serve (Richter, 1983). Tourists' attitudes are led by cultural values and reflected in buying behaviour (Reisinger \& Turner, 2002).

\subsection{Importance of Culture}

Culture plays a crucial role and influences personal behaviours regarding green products. Tseng and Hung (2013) and Ritter et al. (2015) found that personality traits are important and that collectivistic and individualistic cultures affect purchase intentions differently. Purchasing of green tourism products is influenced by individuals' behavioural consideration of the environmental effects when buying using and disposing of products (Liu et al., 2019). Studies have also highlighted that the environmental concerns and beliefs of consumers from developing countries drive different attitudes than those in developed countries.

American anthropologists Kroeber and Kluckhohn (1952) provided 164 different definitions of culture. Over the past two decades, the word "culture" has come to embrace both national and organisational values and behaviour. Many scholars apply an international perspective when looking at differences. For example, scholars focusing on cultural issues refer to age, generation and communities (Soderberg \& Holden, 2002). Hofstede (1980) highlighted that culture is the "software of the mind" that individuals acquire in their childhood and in educational institutions through "mental programming". Furthermore, culture is something that members of a community "have" or "belong" to. In short, culture can be regarded as social variation, diversity and power relations within nations (Soderberg \& Holden, 2002). The essentialist concept of culture can be associated with consumer tastes and demand.

Many previous studies provided a road map in culture definition. Culture is the way of life of a particular group of people and represents a guide to behavioural interpretation. (Harris \& Moran, 1979; Barnlund \& Araki, 1985) Culture includes systems of values, symbols and meaning (Kim \& Gudykunst, 1988; Hofstede, 1980). Hall (1965) viewed culture as a communication system that provides values, beliefs, perceptions and norms and facilitates humans' perceptions of the world. Triandis (1972) extended the meaning of culture and added other elements.

Kluckhohn and Strodtbeck (1961) suggested that cultures can be characterised by their value orientations towards five elements: humans (human beings may perceived as good or a mixture of good and evil); nature (humans may be subjected to nature, live in harmony with nature or control nature); activity ("being", "becoming" or "doing”); time (past, present and future); and relationships between people, which can be lineal (hierarchical relationship), collateral (group relationship) or individual (individual goals take primacy over group goals).

Although cultural differences may lead to different values, beliefs and norms and result in different attitudes and buying decisions (Reisinger \& Turner, 2002), the literature on the buying decisions of Asians and non-Asians in rela- 
tion to green tourism products has not often been very explicit or reflective about these cultural differences. Therefore, this study aimed to fill these research gaps left by previous studies (Liu et al., 2019; Reisinger \& Turner, 2002).

\subsubsection{Cultural Difference and Tourists' Green Behaviour}

National culture has an important intervening effect on tourist behaviour (Pizam \& Telisman-Kosuta, 1989). Differences between cultures are often evident at the different national level (Reisinger \& Turner, 2002). Very often, cultural differences are found in values related to roles, status, class, attitudes, perceptions, patterns of interaction, relationships, verbal and nonverbal language, communication and services (Bochner, 2007; Wei, Crompton \& Reid, 1989). Cultural differences can be small or large. Large cultural differences may create cultural conflict between a host population and tourists (Wei, Crompton, \& Reid, 1989). Such conflict is related to value systems, lifestyle, individual behaviour, expectations, traditions, safety levels and moral conduct (Mathieson \& Wall, 1982). Reisinger and Turner (2002), who highlighted cultural differences demonstrated through behavioural characteristics and lifestyles.

Non-Asians have highly positive attitudes towards the natural environment (Tikka et al., 2000). Such environmental awareness induces a positive attitude towards eco-friendly activities and encourages people to engage in ecologically friendly behaviour (Kalafatis et al., 1999). Eco-friendly attitudes are strongly associated with individual perceptions of the importance of the environment (Laroche et al., 2001). Individuals with strongly eco-friendly attitudes understand the importance of being environmentally friendly and strive to be environmentally responsible (Han et al., 2019). Asian tourists tend to be more concerned about budgets and shopping while they are travelling (Mey et al., 2006).

Ayala (1996) early examined the German and American travel markets and found that environmental considerations were a significant element in travellers' destination-choosing processes. This study found that Europeans were willing to pay $20 \%$ more for a naturally preserved environmental holiday (Ayala, 1996). Hudson and Ritchie (2009) stated that many Canadian visitors consider the environmental record of a company and destination when making holiday reservations. Many green tourists prefer to make contributions to the preservation and enhancement of the natural environment. Another study demonstrated that approximately 59\% of Austrian skiers were prepared to pay an "environmental tax" that would be used for protecting the environment in their chosen holiday resort (Hudson \& Ritchie, 2009).

Choosing green tourism products is not limited to non-Asian tourists. Studies have found that Asians are increasingly concerned about humanity's relationship with nature. A belief that nature and humans should be in harmony with the environment is the main reason why many Asians tend to prefer green products (Chan, 1999). However, Liu et al. (2019) argued that in many Asian countries, awareness of green consumption is lagging behind, and their cultural values potentially influence their green product purchasing decisions. 
Reisinger and Turner (2002) claimed that cultural differences in social behaviour affect the amount of leisure time spent on various tourism products and travel behaviour. Scholars (Reisinger \& Turner, 2002) have highlighted that the cultural characteristics of Asian tourists influence their travel patterns and demand in terms of desired accommodation and buying behaviour. Cultural differences may also affect the service quality expectation of a service organisation. When tourism providers face cultural differences, the difference between what guests expect and what providers think the guests expect may be large (Zeithaml, Parasurman \& Berry, 1990). Globalisation and convergence of cultural spaces in Europe comprise a general system of priority values, stereotypes of social behaviour, lifestyle patterns, morals and spiritual standards. The process of cultural convergence in Europe is increasing due to the Eastern and Central European cultural space, contributing to a shift in the concept of green product purchase behaviour (Liobikiene \& Mandravickaite, 2011).

Several studies have claimed that the Chinese exhibit cultural values that could potentially drive green consumption (Chan, 1999; Liu et al., 2019). Although the Chinese cannot represent all Asian societies, they have a substantial influence on Asian culture because of China's large population. Kluckhohn and Strodtbeck (1961) discussed five elements of Chinese culture: 1) man-in-nature orientation; 2) man-himself orientation; 3) relational orientation; 4) past time orientation and 5) activity orientation. The man-in-nature orientation determines the relationship between humans and the natural environment. The Chinese recognise the scholarly emphasis of the Tao Te Ching, the great philosophical work by Lao Tzu. Therefore, the Chinese perceive that flowers, trees and grass have their own "consciousness" and should not be destroyed without good cause. Traditional cultural attitudes dictate that Chinese people should live in accordance with the ways of nature.

Marketers frequently use Hofstede's cultural dimensions that are linked to global consumer culture when examining green buying behaviour (Cleveland \& Laroche, 2007; Millan et al., 2013). Hofstede and Bond (1988) adopted the Values Survey Module and used various elements that affect culture to measure different perspectives, including 1) power distance, the tolerance for a class differential in society, including high power distance and low power distance; 2) individualism, the degree to which the welfare of the individual is valued more than that of the group; 3) masculinity, which is based on achievement orientation, competition and materialism; 4) uncertainty avoidance, i.e., intolerance of risk; and 5) a Confucian dynamic or long-term orientation based on stability, thrift and respect for tradition and the future.

Hofstede (1991) concluded that Asian societies tend to score high on long-term orientation, collectivism and power distance and are mixed in terms of masculinity and uncertainty avoidance characteristics. Non-Asian societies tend to score low on long-term orientation, collectivism, power distance and uncertainty avoidance and are mixed in terms of masculinity. The masculinity 
index was selected because it measures cultural traits that are assertive and it has less concern for feelings compared with other indices (Crotts \& Erdmann, 2000). Hofstede's assumptions about culture have seldom been challenged. However, he overlooked developing countries in his cultural categorisations, and there is a need to rethink the theoretical foundation when applying it to the tourism context.

\section{Methodology}

An exploratory qualitative research design was adopted in this study with Asian and non-Asian visitors to Macau as the target respondents. The data were collected through in-depth interviews with the visitors at an airport departure hall, a ferry terminal and local tourist attractions. The interviews used open-ended questions, and the data were analysed using a grounded theory framework. A total of 15 Asian and 15 non-Asian visitors were selected by purposive sampling. (Scott, 2004) This sample size is considered sufficient to reach information saturation. Some authors (Crouch \& McKenzie, 2006; Guest, Bunce, \& Johnson, 2006) have asserted that a good sample for a qualitative study is between 15 and 20 homogeneous interview participants. The interviews took one hour and were audio-recorded and completely transcribed.

Questions were guided by an interview script with bilingual versions that were produced in English and traditional Chinese using the back-translation method. A fact sheet was provided for visitors prior to the interviews to enable them to reflect on the study's area of concern, namely green tourism products. The interviews took place in a quiet area to help the participants feel free to share their comments in relation to green tourism product purchase choices and their buying intentions. The data were summarised and organised according to the themes generated by the literature review. Summaries of the interviews were also prepared to highlight the main concepts that emerged and set the context for selecting quotes from the participants' comments, which are provided as examples in the research report.

The data analysis and coding were conducted in several stages. The generated codes were categorised and displayed in themed charts. Domain analysis was used to describe and analyse each theme separately. The coding results at different levels were compared to explore differences in opinions and suggestions.

\section{Results and Discussion}

Dworkin (2012) asserted a minimum sample size required to reach saturation and redundancy in grounded theory. Therefore, answer from the thirty interviewees their comments were up to information saturation. The interviews were completed within four weeks. The interviewed visitors came from 11 different countries (China, Japan, South Korea, Vietnam, the United States, the United Kingdom, France, Canada, the Dominican Republic, Russia and Germany). Their ages ranged from 22 - 60 years; 17 were female and 13 were male. The interviews were conducted in comfortable places such as coffee shops or waiting 
areas in the departure lounge to encourage deeper responses. Consent forms, key questions and information fact sheets were provided to the respondents for review to ensure that they fully understood the objectives of the study. The interviews were recorded and drop down the notes by using a computer to guarantee the absence of misunderstanding. Content analysis was used to analyse the data. The raw data were highlighted and classified according to different themes for further discussion.

Table 1 presents a comparison of themes mentioned by Asian and non-Asian

Table 1. Themes arising from interviews with Asian and non-Asian visitors from Macau

\begin{tabular}{|c|c|c|}
\hline $\begin{array}{l}\text { Green tourism } \\
\text { product concept }\end{array}$ & Asian visitors & Non-Asian visitors \\
\hline Theme & Categories & \\
\hline Values & $\begin{array}{l}\text { - Environmental mindset } \\
\text { - Trendy concept } \\
\text { - Background and experiences } \\
\text { - Policy and regulation implemented by the government } \\
\text { - Health and longevity }\end{array}$ & $\begin{array}{ll}\text { - } & \text { Trendy concept } \\
\text { - } & \text { Individual values } \\
\text { - } & \text { Lifestyle symbol }\end{array}$ \\
\hline Attitudes & $\begin{array}{l}\text { - Education } \\
\text { - Peers effect } \\
\text { - Nature will effect human attitudes; Materialism society } \\
\text { - } \text { pays less attention to green approach } \\
\text { - } \text { conceptoped countries are more concerned about green } \\
\text { - } \text { Developing countries are unaware of green concepts } \\
\text { - Knowledge elicits awareness } \\
\text { - Technological influences lead to attention }\end{array}$ & $\begin{array}{l}\text { - Education } \\
\text { - Personal attitudes and beliefs } \\
\text { - Attention to the planet } \\
\text { - Eco concept yields green concepts } \\
\text { - Social media promotes green concepts } \\
\text { - Culture affects vision } \\
\text { - Countries adopt green attitudes } \\
\text { - Developed countries are more concerned about green } \\
\text { - } \text { concept than developing countries are } \\
\text { - Pricing and quality } \\
\text { - Different segments mean different attitudes } \\
\text { - Willingness to pay } \\
\text { - Asians look for quantity, whereas non-Asians look for } \\
\text { sustainability }\end{array}$ \\
\hline $\begin{array}{l}\text { Green purchase } \\
\text { behaviour }\end{array}$ & $\begin{array}{l}\text { - Religious conviction leads to buying behaviour } \\
\text { - Culture effect to purchasing decision } \\
\text { - Focus on pricing } \\
\text { - Asians have low level of attention } \\
\text { - China's attention to green concepts is limited to } \\
\text { - } \text { governmental promotion } \\
\text { - Conceptually based } \\
\text { - Different interests, values and action } \\
\text { - Asians are passive; non-Asians are active } \\
\text { - Chinese was a late comers in their attitude towards this } \\
\text { behaviour, whilst non-Asians are early adopters }\end{array}$ & $\begin{array}{l}\text { - Norms and habits } \\
\text { - Social and disposable income } \\
\text { - Environmental commitment } \\
\text { - Asians are not concerned, whereas non-Asians take action } \\
\text { - Non-Asians prefer attention to authenticity and quality } \\
\text { - Asians focus on profit making } \\
\text { - Non-Asians focus on industrial development } \\
\text { - Asians catch up late, whereas non-Asians are well developed } \\
\text { - Optional behaviour } \\
\text { - More visible action is observed among non-Asians than } \\
\text { - } \text { among Asians } \\
\text { - } \text { Context } \\
\text { - Nopular in the non-Asian context than in the Asian } \\
\text { that Asians }\end{array}$ \\
\hline
\end{tabular}


visitors regarding green values, attitudes and buying behaviour. The table shows the major themes grouped according to the research questions. The results show that cultural background positively affects attitudes towards tourism green products, including green consciousness and purchase intention. Influence factors are based on different cultural values in different groups. Asians tend to be influenced by government policies, whereas non-Asians are influenced by their personal norms and beliefs. The green attitudes of Asian and non-Asian visitors also differ. Asians are mainly aware of green issues because of their religious conviction that motivates their buying behaviour. For instance, the Chinese believe in a man-in-nature concept and that the natural environment should not be harmed. Non-Asians' attitudes are guided by their ecological concepts. Therefore, their practices tend towards sustainability. Many Asians believe that numerous countries remain underdeveloped and may not be concerned about buying green tourism products. By contrast, non-Asians think that countries are well-developed and they are more concerned about buying green products and tend towards an environmentally friendly approach. Attitudes towards pricing also differ between the two groups. Asians are more focused on pricing than non-Asians, whereas non-Asians value quality over pricing.

\subsection{Different Valuations of Green Concepts in Asian and Non-Asian Societies}

Most of the respondents exhibited different viewpoints on the value of green concepts. Most of the Asians perceived that green consciousness is based on how the government educates people and implements policy. Their valuation of green concepts was also based on their background and experiences. If the Asian respondents had used a green product, then they were likely to have an awareness of green issues. Chinese respondents claimed that certain environmentally friendly mindsets would drive them towards a green concept, and they expect to be healthy and have a long life. The value concepts of the Chinese are thus linked to man-in-nature.

Non-Asian respondents were more likely to think of green issues in terms of a stylish and trendy concept than the Asian respondents were. They viewed green consciousness as an individual value that could be exhibited in someone's lifestyle by adopting green products. The Asian participants' comments reflect that product quantity and pricing were more important to them than other factors. Non-Asians perceived product sustainability as more important than other factors. The difference is likely to be due to perceptions based on different knowledge and awareness of green concepts, as illustrated by the following examples:

"Chinese believe in nature environment should harmony with human society. In addition, people who are particularly concerned about their health and are from a culture that values longevity will pay attention to a green tourism product." (P10, Chinese).

"In the West, environmentalism seems more of a passing fad than a life- 
style" (P30, American).

\subsection{Differences in Culture and Environmental Consciousness Affect Preferences for Green Tourism Products}

Asians and non-Asian participants alike claimed that if visitors are conscious about their planet, then they are likely to purchase green tourism products. Popular technologies and social media create considerable attention and promote green concepts. Both groups agreed that education is a crucial factor to create awareness of environmentally friendly attitudes. The non-Asian participants mentioned eco-concepts and promoting green concepts more than the Asian participants did. Asian participants identified that knowledge leads to awareness and would be likely to draw people's attention to green concepts. Non-Asian participants believed that personal values would drive green attitudes, whereas Asian participants were more likely than non-Asians to be affected by their peers' views on green products. Asian culture and environmental consciousness is highly focused on people's relationship with nature and human attitudes. The non-Asian participants believed that culture and environmental consciousness depend on personal attitudes and beliefs. Several non-Asian participants pointed out different factors that influence their buying attitudes towards green tourism products. Asians and non-Asians agreed that people in developing countries pay less attention to green products than those in developed countries do, and people in developed countries are more concerned about environmental issues and the planet than those in developing countries are. Asian participants perceived that materialistic societies pay little attention to green concepts. Comments provided by non-Asian participants suggested that pricing was sometimes more important than environmental consciousness, particularly during family holidays or for budget travellers.

"In my opinion, attitudes do not change because of differences in cultures. I think attitudes highly depend on the level of education" (P39, Austrian).

"With the development of technology and science, people's living standards have improved. Nowadays, a growing number of people focus on the significance of protecting the environment. Thus, they will buy green tourism products" (P27, Chinese).

"Given that holidays are a privileged moment in the year, they also represent a budget. Of course, environmental consciousness can affect buying attitudes. However, when it comes to budget travellers or family, feelings such as desire or happiness can win over environmental consciousness. Moreover, it seems hard to reconcile faraway destinations with a reduced carbon footprint, for example" (P32, French).

\subsection{Asian and Non-Asian Cultural Attitudes Lead to Green Product Purchase Intentions}

There were differences in the attitudes of respondents from Asian and non- 
Asian cultures towards purchase intention. Asian respondents claimed that religious conviction and cultural differences would lead to green product purchase intentions. Non-Asian respondents said that social norms and habits drive their purchasing behaviour. A commitment to the environment leads to a change in purchasing behaviour. Asian respondents said that government policy and regulations change attention to the environment and thus buying behaviour, whereas Non-Asians perceived that ethics lead to green attitudes. These attitudes were up to their own decision making. The Asian respondents revealed passive attitudes towards green concepts (usually lead by government), whereas non-Asians had an active approach to green attitudes.

From a marketing perspective, the Asian respondents tended to focus on profit-making from green tourism products, whereas the non-Asians focused on long-term industrial development. This suggests that Asians have a short-term approach, using green concepts to promote their business, whereas non-Asians revealed a long-term orientation based on their views of green concepts.

Non-Asians, including Europeans and people in North America, were early adopters of green attitudes, whereas Asian populations were late adopters. Therefore, the buying decisions of Asians are catching up with those of non-Asians. The Asian respondents had different interests and values in relation to green concepts. The Non-Asians had stronger attitudes towards green concepts than the Asians did. Their comments also demonstrate that they tended to have a high disposable income and were willing to buy green tourism products. The following comments illustrate some of these themes:

"Nowadays, people around the world are more concerned about the environment than before. They invest a lot in the environmental protection industry. For example, a growing number of cities in China implement a garbage classification policy" (P9, Chinese).

"In 2017, the National People's Congress passed the Chinese civil law. This law states that Chinese actions in business should correspond to the green principle" (P22, Chinese).

"In the Asian culture, people's green actions are based on the force of laws and regulations. One example is the required payment for extra plastic bags. Westerners are active, whereas Asians are passive towards environmental values and behaviours" (P25, Korean).

"People are engaged in green behaviours for ethical reasons, but it depends on the level of education. In the Western culture, these behaviours are becoming an ethical duty" (P37, French).

"Asian people don't seem to buy organic food. Moreover, they use a lot of plastic (plastic bags for example). In Western countries, the no-plastic rule, as well as organic food and recycling, is becoming a norm" (P29, UK) "Similar consumption behaviour is displayed in Asian and Western cultures in terms of income and social/cultural status. Green products are nowadays mostly consumed by people with high disposable incomes, and this affir- 
mation can also be applied for tourism products, which are often only accessible for the richest" (P32, German).

\section{Asian and Non-Asian Attitudes towards Green Tourism Products from Hofstede's Perspective}

This study identifies differences between Asian and non-Asian tourists that are affected by the culture, values, beliefs and norms guiding their perceptions and buying decisions. The findings suggest that cultural differences in knowledge and educational background may affect views about green products and buying decisions. Although Asians and non-Asians have different values and norms, it seems that the understanding of green concepts and acknowledging the impact of green decisions influences their decision making. Pricing is the main determinant of the decision to buy green tourism products for both Asians and non-Asians. Guided by Hofstede's theory (1988), the evidence demonstrates that cultural difference affects attitudes to choice and purchase intention, as discussed below.

\subsection{Power Distance}

Different values were identified for high and low power distance countries. Asian visitors' green values and attitudes are based on governmental policy and regulations. The interviews suggested that the green values and concepts of the Asians are heavily influenced by government policy and its implementation. Consumers value conformity and behave as they are told to do, which reflects the man-in-nature concept. Non-Asians are seldom affected by their government. They have individual norms and habits that affect their buying behaviour.

\subsection{Individualism}

Individualism differs across cultures. Non-Asians form their values and attitudes based on their personal norms and habits, whereas Asians are commonly affected by their peers or the government. The interviews suggest low levels of individualism among Asian tourists, as their green attitudes are led by government policy. A tendency for people to belong to groups that look after each other in exchange for loyalty is also evident. In China, policies to stimulate the green behaviour of buyers are also common. Concerned with enhancing the ecological knowledge of the population, the country's educational systems endeavour to educate people via various social media platforms.

In contrast, high individualism is found among non-Asian groups, who apply their own values to their attitudes and purchase intentions. Autonomy is highly valued and inner-directed, and it motivates individual decisions to buy green products. Non-Asians are not obliged to consult with their governments and groups. Asian visitors' buying behaviour is likely to be passive, whereas nonAsians are likely to take an active approach. Non-Asians apply their inner values to evaluating green products and services. They are innovative consumers and 
accept green tourism products.

\subsection{Masculinity}

The findings reveal that Asian and non-Asian tourists have different viewpoints about green issues in terms of high-masculinity and low-masculinity societies. Numerous non-Asians mentioned that developed countries are more concerned about green concepts than developing countries are. A society high in materialism (which is seen as a masculine trait) pays little attention to green issues, whereas a feminine society shows concern for the environment and places high importance on environmental preservation. A low-masculinity society prefers ethical behaviour, whereas a high-masculinity society favours pricing in purchasing behaviour. Several non-Asian visitors stated that Asians focus on profit-making and are not concerned about the environment. Non-Asians also claimed that they were willing to pay a premium for a green tourism product despite its high price. However, when a family plans for a vacation, members occasionally consider price to be more important than the environment. Therefore, a high-masculinity culture can align with green attitudes and purchasing behaviour but also pay little attention to green concepts.

\subsection{Uncertainty Avoidance and Long-Term Orientation}

Uncertainty avoidance indicates the degree to which people felt threatened by ambiguity and uncertainty and the degree to which a culture is willing to try or accept a new product. A considerable number of non-Asian visitors exhibited a stronger acceptance of green products than Asian visitors did. Asians focus on contemporary green tourism products, whereas non-Asians are considered early adopters. Non-Asians have a strong sense for novel green products and concern for the environment. Traditional Chinese tourists view their relationship with nature in the context of the advent of modernisation. They believe that their religious code asserts that human beings should avoid exploiting the environment and respect the intrinsic way of nature (Chan, 1963). The interviews revealed that that Asians, particularly the Chinese, are more concerned about nature than non-Asians. They believe that humans should align with nature. Therefore, there is an interrelationship among the different forces that shape the green purchasing behaviour of Chinese visitors. Based on Chinese cultural values, "man-in-nature" influences eco-friendly behaviour: cultural values have an impact on an individual's feelings about green concepts and thus affect his or her attention and buying behaviour.

\section{Implications for Practitioners}

Non-Asian and Asian visitors' cultural differences lead to differences in environmental consciousness, which affects their attitudes and buying behaviour. Marketers of green tourism products are advised to consider the following factors when implementing their marketing strategies: pricing, purchasing power, 
the influencing power of the government and peers, segmenting different markets for green tourism products, selecting the appropriate distribution channel and improving the quality of green products.

Paying attention to all of these factors has the potential to create great marketing return in the long run. When applying the results of this study to practical marketing planning, marketers of international green tourism should consider the following points when designing campaigns for green tourism products.

Messages from marketers should stimulate emotional appeal for Asians because their attitudes are influenced by peers and the government. Promotional messages could include a positive notion such as "we can take care of the Earth", "together, we can do something for the Earth" or "we can survive on Earth". Marketers could target certain reference groups or opinion leaders to deliver messages to their peers and locals. The strong power of peer influence suggests a group effect in environmental behaviour among Asian visitors. Significant group attitudes and networks can suggest, cultivate, circulate and reinforce a set of pro-environmental values and behavioural norms in Asian societies. Group values demonstrate the collectivistic Chinese culture, whereas non-Asians are affected by individuals and are expected to conform to large social norms (Hofstede et al., 1988).

The findings also suggest that marketers should segment the visitor market and provide the right green products for the right customers. Young people and families may need different promotion and marketing strategies. Young people should be motivated by intrinsic values in relation to environmental protection and be rewarded by a sense of feeling great about themselves during their green purchases, whereas families should be informed about pricing and educational issues. Pricing is a considerable concern among both Asian and non-Asian groups. Therefore, marketers should focus on special pricing strategies, particularly for special groups. Non-Asians may respond to pricing aligned with quality issues. Marketers can focus on added value for the customers.

Tourism marketers can also adopt buzz marketing campaigns that encourage positive word-of-mouth regarding environmental protection. They may adopt strategies that make use of social media platforms to deliver green messages. Green purchasing communication and interaction with visitors may work for non-Asian visitors. Marketers can focus on quality and sustainability issues when promoting green products to these visitors.

Marketers' information for visitors can also be informed by Asians' religious codes. For instance, the Chinese value human-nature harmony. Asian tourists' green purchasing behaviour requires emotional involvement because environmental protection embeds the ideas of human-nature harmony and love of motherland. Thus, religious conviction influences buying behaviour in relation to green products.

Perceived environmental responsibility is a predictor of green purchasing behaviour. The environmental responsibility of non-Asian visitors is strongly eco- 
centric and represents relational orientations that have become socialised. Promoting future green tourism products to non-Asian visitors can emphasise individual responsibility to protect the environment.

Cultural values may exert a significant impact on an individual. This paper demonstrates that Asian tourists' values significantly demonstrate an ecological effect but ecological knowledge is weak in general. Their traditional cultural values influence this ecological effect and green purchasing behaviour. Marketers must understand how cultural values shape people's eco-friendly behaviour. Cultural values also have an impact on individuals' accumulated feelings about things, and these values do not necessarily enhance cognitive understanding of those things.

\section{Theoretical Implications}

According to Hofstede's cultural dimensions (1988), cultural differences are not limited to power distance, individualism, masculinity, uncertainty avoidance and long-term orientation. Cultural differences are found in knowledge awareness and education. Visitors tend to be highly educated and knowledge may affect their buying decisions and attitudes. Scholars (Hofstede et al., 1988; Liu et al., 2019) have noted that perception leads to values and norms; education is a major source of perceived values and knowledge elicits awareness. A good educational background and knowledge will directly affect attitudes and buying decision.

The purchase decisions of tourists from developing countries with strong collectivist values such as China will be affected by peers and family members. If people have many friends who buy green products, they might feel they are doing the right thing if they also buy those products.

Our results echo previous studies and confirm that Asians tend to be increasingly concerned about man-in-nature. As a result, many Asians tend to prefer green products (Chan, 1999). However, we found that many Asian tourists are willing to pay for budget tourism products and unwilling to buy green tourism product according to pricing considerations. Asians also pay little attention to buying green tourism products.

As mentioned above, non-Asians have highly positive attitudes towards the natural environment (Tikka et al., 2000). Such environmental awareness induces a positive attitude towards eco-friendly activities and encourages non-Asians tourists to engage in ecological actions. This might be because they view green products as a trendy and stylish symbol.

Our results support increasing the body of literature that argues that Hofstede's model should be extended. In sum, the study provides evidence that cultural difference affects the buying attitudes and purchasing behaviour of Asian and non-Asian tourists in terms of green tourism products. Hofstede's five cultural dimensions (1988) should be expanded to include knowledge, education and peer influence, as these also influence cultural difference. Subjective factors 
such as pricing and willingness to pay for green tourism products also affect the choices of tourists.

\section{Conclusions and Limitations}

The study adopted qualitative approach for guiding the study as result to understand the different perspective between Asians and non-Asians visitors. Global awareness of environmental degradation has been a long-time concern. The increasing affluence derived from rapid economic growth has encouraged certain sectors of society to realise the impact of environmental deterioration. This realisation creates new challenges and opportunities for tourism policymakers and green marketers.

Interviews with Asian and non-Asian visitors demonstrate that cultural background strongly influences attitudes and buying behaviours in relation to green tourism products. Overall, visitors' attitudes and buying behaviours are governed by their level of knowledge and their values. Asian visitors are likely to be affected by their long-term orientation and man-in-nature concept. Non-Asian visitors are likely to be affected by individual concepts and norms about sustainability. Power distance is demonstrated among Asian visitors and affects their green purchase intention, particularly for Chinese visitors. This deep understanding of the process and antecedents of green purchases provides governments and marketers of green tourism with beneficial insights into improving the communication effectiveness of their various environmental campaigns.

Owing to limited resources, this study was based on a small sampling of Asian and non-Asian visitors. This sample may not be representative of the global population. However, we believe that this survey contributes to an in-depth understanding of the underlying factors accounting for the performance of eco-friendly purchasing in numerous developed and developing countries. For future study should be viewed as a foundation for follow-up research regarding the perspectives of different segments of visitors.

\section{Acknowledgements}

Appreciated Ms. Tirouflet Justine collected the data and information out of Macau which made the completion of this research.

\section{Conflicts of Interest}

The authors declare no conflicts of interest regarding the publication of this paper.

\section{References}

Agarwal, B. (2000). Conceptualizing Environmental Collective Action: Why Gender Matters. Cambridge Journal of Economics, 24, 283-310.

https://doi.org/10.1093/cje/24.3.283

Ayala (1996). Intelligent Agents to Support the Effective Collaboration in a CSCL Envi- 
ronment. Waynesville, NC: Association for the Advancement of Computing in Education (AACE).

Barnlund, D., \& Araki, S. (1985). Intercultural Encounters: The Management of Compliments by Japanese and Americans. Journal of Cross Cultural Psychology, 16, 9-26. https://doi.org/10.1177/0022002185016001002

Bochner, S. (2007). Coping with Unfamiliar Cultures: Adjustment or Culture Learning? Australian Journal of Psychology, 38, 347-358. https://doi.org/10.1080/00049538608259021

Chan, R. Y. K. (1999). Environmental Attitudes and Behaviour of Consumer in China: Survey Finding and Implication. International Journal of Consumer Marketing, 11, 25-52. https://doi.org/10.1300/J046v11n04_03

Chan, W. T. (1963). The Way of Lao Tsu. New York: Bobbs-Merrill.

Cheung, M. F. Y., \& To, W. M. (2019). An Extended Model of Value-Attitude-Behavior to Explain Chinese Consumers' Green Purchase Behaviour. Journal of Retailing and Consumer Services, 50, 145-153. https://doi.org/10.1016/j.jretconser.2019.04.006

Cleveland, M., \& Laroche, M. (2007). Acculturation to the Global Consumer Culture: Scale Development and Research Paradigm. Journal of Business Research, 60, 249-259. https://doi.org/10.1016/j.jbusres.2006.11.006

Crotts, J., \& Erdmann, P. (2000). Does National Culture Influence Consumers' Evaluation of Travel Services? A Test of Hofstede's Model of Cross-Cultural Differences. Managing Service Quality: An International Approach, 10, 410-419.

https://doi.org/10.1108/09604520010351167

Crouch, M., \& McKenzie, H. (2006). The Logic of Small Samples in Interview-Based Qualitative Research. Social Science Information, 45, 483-499.

https://doi.org/10.1177/0539018406069584

Dworkin, S. (2012). Sample Size Policy for Qualitative Studies Using In-Depth Interviews. Archives Sexual Behavior, 41, 1319-1320. https://doi.org/10.1007/s10508-012-0016-6

Guest, G., Bunce, A., \& Johnson, L. (2006). How Many Interviews Are Enough? Field Method, 18, 59-82. https://doi.org/10.1177/1525822X05279903

Hall, E. (1965). The Silent Language. Greenwich, CT: Fawcett.

Han, H., Moon, H., \& Hyun, S. (2019). Uncovering the Determinants of Pro-Environmental Consumption for Green Hotels and Green Restaurants. A Mixed-Method Approach. International Journal of Contemporary Hospitality Management, 32, 1581-1603. https://doi.org/10.1108/IJCHM-04-2019-0354

Harris, M., \& Moran, R. (1979). Managing Culture Differences. Houston, TX: Gulf.

Hofstede, G. (1980). Culture's Consequences: International Differences in Work-Related Values. Beverly Hills, CA: Sage.

Hofstede, G. (1991). Culture and Organizations: Software of the Mind. London: McGrawHill.

Hofstede, G., \& Bond, M. (1988). The Confucius Connection: From Cultural Roots to Economic Growth. Organizational Dynamic, 16, 5-21. https://doi.org/10.1016/0090-2616(88)90009-5

Homer, P. M., \& Kahle, L. R. (1998). A Structural Equation Test of the Value-AttitudeBehaviour Hierarchy. Journal of Personality and Social Psychology, 54, 638-646. https://doi.org/10.1037/0022-3514.54.4.638

Hudson, S., \& Ritchie, B. (2009). Understanding and Meeting the Challenges of Consumer/Tourist Experience Research. International Journal of Tourism Research, 11, 
111-126. https://doi.org/10.1002/jtr.721

Kalafatis, S. P., Pollard, M., East, R., \& Tsogas, M. H. (1999). Green Marketing and Ajzen's Theory of Planned Behaviour: A Cross-Market Examination. Journal of Consumer Marketing, 15, 441-460. https://doi.org/10.1108/07363769910289550

Kim, H. Y., \& Chung, J. E. (2011). Consumer Purchase Intention for Organic Personal Care Products. Journal of Consumer Marketing, 28, 40-47. https://doi.org/10.1108/07363761111101930

Kim, Y., \& Gudykunst, W. (1988). Theories in Intercultural Communication. International and Intercultural Communication Annual Vol. 12. Newbury Park, CA: Sage.

Kluckhohn, F. R., \& Strodtbeck, F. L. (1961). Variations in Value Orientation. New York: Harper and Row.

Kotchen, M. J., \& Reiling, S. D. (2000). Environmental Attitudes, Motivations and Contingent Valuation of Non-Use Values: A Case Study Involving Endangered Species. Ecological Economics, 32, 93-107. https://doi.org/10.1016/S0921-8009(99)00069-5

Kroeber, A. L., \& Kluckhohn, C. (1952). Culture: A Critical Review of Concepts and Definitions. Papers of the Peabody Museum of American Archaeology and Ethnology, Harvard University, Vol. 47, No. 1, viii, 223, Cambridge, MA: The Museum.

Kumar, B., Manrai, A. K., \& Manrai, I. A. (2017). Purchasing Behaviour for Environmentally Sustainable Products: A Conceptual Framework and Empirical Study. Journal of Retail Consumer Service, 34, 1-9. https://doi.org/10.1016/j.jretconser.2016.09.004

Laroche, M., Bergeron, J., \& Barbaro-Forleo, G. (2001). Targeting Consumers Who Are Willing to Pay More for Environmentally Friendly Products. Journal of Consumer Marketing, 18, 503-520. https://doi.org/10.1108/EUM0000000006155

Lin, P. C., \& Huang, Y. H. (2012). The Influence Factors on Choice Behaviour Regarding Green Products Based on the Theory of Consumption Values. Journal of Clean Production, 22, 11-18. https://doi.org/10.1016/j.jclepro.2011.10.002

Liobikiene, G., \& Mandravickaite, J. (2011). Achievements of Lithuanian Sustainable Development during the Integration Process into the European Union. Technological and Economic Development of Economy, 17, 62-73.

https://doi.org/10.3846/13928619.2011.554000

Liu, M. T., Liu, Y. D., \& Mo, Z. Y. (2019). Moral Norm Is the Key: An Extension of the Theory of Planned Behaviour (TPB) on Chinese Consumers' Green Purchase Intentions. Asia Pacific Journal of Marketing and Logistics.

Manaktola, K., \& Jauhari, V. (2007). Exploring Consumer Attitudes and Behaviour towards Green Practices in the Lodging Industry in India. International Journal of Contemporary Hospitality Management, 19, 364-377. https://doi.org/10.1108/09596110710757534

Mathieson, A., \& Wall, G. (1982). Tourism: Economic, Physical and Social Impacts. New York: Longman.

Mayo, E., \& Jarvis, L. P. (1981). The Psychology of Leisure Travel: Effective Marketing and Selling of Travel Service. Boston, MA: CBI.

Mey, L. P., Akbar, A. K., \& Dyg, F. (2006). Measuring Service Quality and Customer Satisfaction of the Hotels in Malaysia: Malaysian Asian and Non-Asian Hotel Guests. Journal of Hospitality and Tourism Management, 13, 144-160. https://doi.org/10.1375/jhtm.13.2.144

Millan, A. L. et al. (2013). Knowledge Management and the Effectiveness of Innovation Outcomes: The Role of Cultural Barriers. Electronic Journal of Knowledge Management, 11, 62-71. 
Miller, G. (2001). Corporate Responsibility in the UK Tourism Industry. Tourism Management, 22, 589-598. https://doi.org/10.1016/S0261-5177(01)00034-6

Penny, W. Y. K. (2007). The Use of Environmental Management as a Facilities Management Tool in the Macao Hotel Section. Facilities, 25, 286-295. https://doi.org/10.1108/02632770710753325

Pereira, E. M. V., Mykletun, R. J., \& Hippolyte, C. (2012). Sustainability, Daily Practices and Vacation Purchasing: Are They Related? Tourism Review, 67, 40-54. https://doi.org/10.1108/16605371211277812

Pizam, A., \& Jeong, G. H. (1996). Cross-Cultural Tourist Behavior: Perceptions of Korean Tour Guides. Tourism Management, 17, 277-286. https://doi.org/10.1016/0261-5177(96)00019-2

Pizam, A., \& Sussman, S. (1995). Does Nationality Affect Tourist Behaviour? International Journal of Hospitality Management, 16, 127-145. https://doi.org/10.1016/S0278-4319(97)00001-7

Pizam, A., \& Telisman-Kosuta (1989). Tourism as a Factor of Change; Result and Analysis. In Tourism as a Factor of Changes: A Social Cultural Study(Vol. 1, pp. 149-156).

Reisinger, Y., \& Turner, L. W. (2002). Cultural Differences between Asian Tourist Markets and Australian Host, Part 1. Journal of Travel Research, 40, 295-315. https://doi.org/10.1177/0047287502040003008

Richter, L. (1983). Political Implications of Chinese Tourism Policy. Annals of Tourism Research, 10, 347-362. https://doi.org/10.1016/0160-7383(83)90064-6

Ricky, Y. K., Chan, \& Lau, L. B. Y. (2000). Explaining Green Purchasing Behavior a Cross-Cultural Study on American and Chinese Consumers. Journal of International consumer Marketing, 14, 9-40.

Ritter, A. M., Borchardt, M., Vaccaro, G. L. R., Pereira, G. M., \& Almeida, F. (2015). Motivations for Promoting the Consumption of Green Products in an Emerging Country: Exploring Attitudes of Brazilian Consumers. Journal of Clean Production, 106, 567-520. https://doi.org/10.1016/j.jclepro.2014.11.066

Scott, W. (2004). Reflections on a Half-Century of Organizational Sociology. Annual Review of Sociology, 30, 1-21. https://doi.org/10.1146/annurev.soc.30.012703.110644

Singh, N., \& Gupta, K. (2013). Environmental Attitudes and Ecological Behaviour of Indian Consumers. Social Responsibility Journal, 9, 4-18. https://doi.org/10.1108/17471111311307787

Soderberg, A.-M., \& Holden, N. (2002). Rethinking Cross Cultural Management in a Globalizing Business World. International Journal of Cross Cultural Management, 2, 103-121. https://doi.org/10.1177/147059580221007

Soderbert, A.-M., \& Holden, N. (2002). Retinking Cross Cultural Management in Globalizing Business World. Cross Cultural Management, 2, 103-121.

Tikka, P., Kuitunen, M., \& Tynys, S. (2000). Effects of Educational Background on Students' Attitudes, Activity Levels, and Knowledge Concerning the Environment. Journal of Environmental Education, 31, 12-19. https://doi.org/10.1080/00958960009598640

Triandis, H. (1972). The Analysis of Subjective Culture. New York: Wiley Interscience.

Tseng, S. C., \& Hung, S. W. (2013). A Framework Identifying the Gaps between Customers' Expectations and Their Perceptions in Green Products. Journal of Clean Production, 59, 174-184. https://doi.org/10.1016/j.jclepro.2013.06.050

Weaver, D. (2008). Indigenous Tourism Stages and Their Implications for Sustainability. Journal of Sustainable Tourism, 18, 43-60. https://doi.org/10.1080/09669580903072001

Wei, L., Crompton, J., \& Reid, L. (1989). Culture Conflicts: Experiences of U.S. Visitors to 
China. Tourism Management, 10, 322-332.

https://doi.org/10.1016/0261-5177(89)90011-3

Yen, G. F., Wang, R. Y., \& Yang, H. T. (2017). How Consumer Mindsets in Ethnic Chinese Societies Affect the Intention to Buy Fair Trade Products: The Mediating and Moderating Roles of Moral Identity. Asia Pacific Journal of Marketing and Logistics, 29, 553-568. https://doi.org/10.1108/APJML-06-2016-0107

Yi, S., Li, X., \& Jai, T. M. (2018). Hotel Guests' Perception of Best Green Practices: A Content Analysis of Online Reviews. Tourism and Hospitality Research, 18, 191-202.

Zeithaml, V., Parasurman, A., \& Berry, L. (1990). Delivering Service Quality. New York: Free Press. 